\title{
EL DERECHO ETNICO ANTE EL DERECHO ESTATAL
}

\author{
Herinaldy Gómez Valencia \\ Universidad del Cauca, Colombia
}

\section{INTRODUCCION}

Cinco siglos después de la llegada de Colón al continente americano, reaparece en el mundo con una intensificación inusitada el problema étnico. En consecuencia comienza a incrementarse en múltiples espacios el interés por esta problemática y bajo perspectivas diversas.

En el espíritu público se registra como tema de curiosidad y exotismo, en los medios masivos de comunicación se presenta como conflictos y tragedias, en los Estados surge como reto a la democracia en la construcción de naciones plurales y multiculturales, en la investigación social se asume como problemas en forma de cultura, etnicidad, derechos de minorías, dinámica histórica entre homogeneidad y diversidad, entre otros.

En Colombia son varios los factores que confluyen para que la cuestión étnica tome una dimensión especial: Es uno de los países con mayor diversidad étnica en el mundo; históricamente las etnias indígenas tienen, una tradición de lucha centenaria; el movimiento indígena a partir de la década del setenta se ha vigorizado, originando prácticas de participación política y luchas reivindicativas al parecer sin parangón en Sur América; a pesar de la penetración del mundo occidental entre las etnias y/o de la participación de éstas en la dinámica económico-social y política del país las comunidades indígenas conservan o han reconstituido sistemas o prácticas de derecho (justicia) diferentes al derecho estatal colombiano.

La conjunción de estos hechos fueron entre otros, los factores que contribuyeron para que la Constitución Nacional de Colombia consagrara en varios de sus artículos un nuevo marco para la relación entre el Estado, la sociedad nacional y los grupos étnicos. Entre los múltiples aspectos que establece la Constitución se encuentra el referido a la regulación de las formas de derecho y justicia étnico s en su articulación con la administración de la justicia o derecho estatal. 
Han pasado tres años largos de promulgada la Constitución y a pesar de la perentoria necesidad de reglamentar el artículo 246, que habla de las jurisdicciones especiales indígenas, no se ha llevado a cabo o mejor no ha sido posible. La razón, no existen hasta el momento propuestas serias por parte del Estado o de las comunidades indígenas, que permitan vislumbrar a corto plazo una reglamentación acorde con la concepción filosófica contenida en el hecho de que Colombia es una república unitaria, conformada por una gran diversidad étnica y cultural. En situación similar parecen encontrarse las reformas constitucionales realizadas anteriormente por otros países: Perú (1979), Guatemala (1985), Nicaragua (1986), Brasil (1988), México (1990), Paraguay (1992).

Uno de los obstáculos mayores para la puesta en práctica de las reformas constitucionales en lo que a la administración de la justicia se refiere obedece entre otros aspectos, al escaso desarrollo de las investigaciones sobre las formas (sistemas) de derecho que poseen las etnias indígenas de América Latina. No obstante esta ausencia, pero consciente de las limitaciones que cualquier planteamiento tiene ante tal carencia, el presente trabajo pretende, a partir de la situación colombiana, enunciar algunos problemas a tener presente en la reflexión antropológica-jurídica, respecto a una posible regulación de los derechos infraestatales o propios de las sociedades ágrafas o de tradición oral, por parte del Estado colombiano.

En el mismo sentido que en un trabajo anterior (1993) identifiqué porqué las formas de justicia indígena constituyen un sistema de derecho (no reducibles a simples prácticas), y cómo sus concepciones filosóficas y formas de producción y ejercicio eran diferentes u opuestas a las del Sistema Judicial Nacional, en ésta reflexión con el ánimo de contribuir al debate, deseo igualmente mostrar algunas oposiciones entre el modelo del derecho moderno y el de las etnias indígenas colombianas.

\section{LA REGULACION DEL DERECHO ETNICO, UN ASUNTO EN CUESTION}

En Colombia, como en muchos otros países latinoamericanos (México, Ecuador, Perú, Bolivia entre otros) las ancestrales y permanentemente reconstituidas formas de existencia y resistencia étnica, de identidad e interculturalidad, han posibilitado la existencia paralela o alternativa de derechos infraestatales o no estatales. 
En efecto, en nuestra nación coexisten no solamente culturas diversas, sino también formas de derecho ancestralmente disímiles. Un derecho escrito, el de la Constitución Nacional, y otros no escritos o infraestatales, propios de las sociedades agrafas o de tradición oral. Sin embargo el derecho escrito no solo es dominante, sino el único constitucionalmente legal, más no por ello el único legítimo, que auto calificándose como de mayor abstracción, universalidad y modernidad, se interpone y arroga el poder de juzgar a los derechos más concretos, específicos y diversos, y en su concepción, casuísticos.

Esta dominación se manifiesta en la existencia de una ley que no admite otras leyes, una verdad jurídica que no admite su constitución bajo otras concepciones, un idioma que menosprecia las lenguas indígenas ni acepta su presencia en los juzgados. ${ }^{1}$ Un derecho que establece: únicas sanciones y condena o invalida otros tipos de control, sanción y rehabilitación, una normatividad jurídica que no reconoce la validez de normas no escritas u orales, unas formas de regulación social que desconoce el desarrollo de otras formas de solucionar conflictos, en fin, un derecho que se ancla sobre la superioridad de la sociedad dominante, para negar o reprimir todas las demás formas de organización social étnica contenidas en sus sistemas de derecho.

La existencia de estas prácticas jurídicas mediante las cuales las étnias indígenas resuelven conflictos autónoma o desarticuladamente del derecho estatal presenta en la actualidad contrastes radicales e irreductibles a las formas de derecho moderno.

La teoría liberal del derecho moderno, asociado al Estado, delimita formalmente (sin que se cumpla en la práctica) las funciones que tocan con su producción, con su ejecución, y con sus mecanismos o procesos para resolver

1 Hasta antes de la Constitución de 1991 el español era el idioma oficial del país y en consecuencia el exigido en las indagatorias de los juzgados. La Constitución de 1991 establece que "Las lenguas y dialectos étnicos son también oficiales en su territorio" (Art. 11). No obstante los juzgados continúan con la inercia de seguir tomando declaraciones en español, a no ser que el procesado alegue el derecho constitucional. Aun así, si el procesado además de su lengua nativa habla el español, la indagatoria obligatoriamente es recibida en su segunda lengua. Para quienes son monolingües nativos se le coloca como traductor a cualquier otro indígena estas fallas son cruciales para los procesados, pues mi experiencia al respecto me ha permitido evidenciar como ante la misma pregunta hecha por el Juez en español pero traducida al idioma nativo y respondida en igual forma, la respuesta obtenida es sustancialmente distinta. Si entrar en detalle y para resaltar la diferencia en el orden de extensión es común encontrar que ante la pregunta "cuente a este despacho en forma detallada como sucedieron los hechos en los cuales usted está implicado?" la respuesta en español, ocupa entre 10 y 20 renglones su transcripción, cuando es hecha en el idioma nativo puede dar lugar a transcripciones que oscilan entre 100 Y 300 renglones. 
y dirimir conflictos. La función de producción la asigna al poder legislativo, la ejecución, al poder ejecutivo, y la adjudicación de derechos, al poder judicial. Esta separación y configuración de poderes al igual que sus denominaciones específicas están ausentes en las formas de derecho no estatales o propias de las etnias indígenas colombianas y al parecer de América Latina. La producción y ejercicio del poder intraétnico deviene o permanece en el espacio de lo comunal o colectivizado y alejado de lo corporativo. En parte la naturaleza de este poder étnico fue lo que condujo a Pierre Clastres a la denominación de "La Sociedad contra el Estado". A esta primera gran diferencia se aúnan otras que es necesario explicitar.

En el derecho moderno la administración de la justicia se produce sobre la combinación de cuatro factores esenciales: La norma escrita o normatividad jurídica, el tribunal, la profesionalización y burocratización jurídica, y la prisión como castigo punitivo, aspectos que en su conjunto configuran un modelo paradigmático que contrasta con el derecho étnico indígena.

La norma escrita es tan cosustancial al derecho moderno, que aún en el derecho consuetudinario anglosajón, los derechos, entre las partes en disputa, se alegan con base a providencias judiciales escritas, referidas a casos similares anteriormente ocurridos. Situación contraria se observa en el derecho indígena en donde la persistencia y aplicación de la norma se fundamenta en la tradición oral o memoria colectiva étnica. Nemotecnia cultural en que los acontecimientos son sometidos una y otra vez a la experiencia vivida y a la inversa, y en donde la versatilidad del conocimiento radica precisamente en su capacidad para adaptarse a las nuevas situaciones o circunstancias. En otras palabras, las llamadas trasgresiones culturales en ocasiones pueden poner en cuestión concepciones de justicia dinamizándolas de tal manara que acontecimientos singulares puedan dar origen a "nuevas" valoraciones o a un ajuste de las concepciones.

El conflicto al ser pensado en el derecho moderno como la disputa entre dos partes "individuales" que reclaman un derecho, estableció la figura de un "neutral" (juez) como representante del Estado para zanjar disputas. De esta forma, la figura de un "neutral”, llámese juez o tribunal, se convirtió en el elemento paradigmático para solucionar conflictos. El derecho indígena en la práctica se opone a la constitución interna de este único mecanismo. Aunque reconoce su existencia en occidente y en ocasiones muy especiales de homocidio remite ${ }^{2}$ después de una valoración interna, las partes en conflicto

2 Puesto que entre las etnias andinas (exceptuando los koguis, arsarios y arhuacos asentados en la Sierra Nevada de Santa Marta, donde el homicidio entre indígenas es prácticamente inexistente -la tradición oral no registra un solo caso, aunque si da cuenta de las muertes cau- 
a los estratos de la justicia ordinaria nacional, intraétnicamente a lo que recurre es a un procedimiento bien diferente. En tanto que lo que busca no es el castigo o la sanción sino la restitución de las partes en conflicto al orden cultural y societal, acuden a la mediación (palabrero entre los wayu, cabildos entre las etnias andinas, shamanes entre las etnias amazónicas), a la conciliación entre las partes o familias directamente afectadas (reparando en parte el daño causado a los dolientes), al Consejo de The'walas entre los paeces, de Mamos entre los arhuacos, koguis y arsarios, de Momarepik entre los guambianos, de Curacas entre los Inganos y kamtzá, etc. Aunque la justicia privada también se da entre las etnias, su práctica es de de carácter espontáneo y en absoluto este proceder prevalece sobre los mecanismos de mediación antes enunciados, a más de que dicha conducta no está apriorísticamente legitimada por la cultura como si lo están la mediación, la conciliación y el consejo.

No se quiere afirmar con esto que la mediación, la conciliación, u otros mecanismos sean propios del derecho indígena, y ajenos al mundo occidental, lo que se desea enfatizar es que el tribunal o juez se ha impuesto como el modelo dominante y hegemónico.

Sobre el particular las investigaciones señalan que: el antiguo derecho griego era una práctica de la indagación de la verdad sin presencia de jueces humanos, sino de dioses. El antiguo derecho germánico estaba gobernado por la lucha y la transación, una especie de ritual de la guerra donde no existía un tercer individuo, un elemento neutro, ni se trataba de saber quién mentía o no, en consecuencia la indagación de la verdad estaba "ausente". El antiguo derecho romano era el proceso de la prueba retórica, un sofisticado ritual verbal o juego discursivo debidamente reglamentado. (Foucault, 1980).

La administración del derecho moderno requiere un sistema burocrático juzgados, tribunales, cortes, etc), cuyo funcionamiento compete totalmente a un estrato profesional, especializado (abogados, jueces, fiscales, magistrados, procuradores, etc). El derecho indígena para su funcionamiento y/o ejercicio no re- quiere de aparatos burocráticos ni de profesionales especializados, por el contrario lo que se encuentra es que los saberes que lo constituyen y

sadas por los blancos o colonos-) en ocasiones remiten los casos de homicidio a los juzgados, es dado pensar, de una parte, que ello evidencia una crisis interna de sus formas de justicia, o de otra, a considerarlo como el proceso de transición que el derecho étnico está viviendo hacia la justicia nacional. Nada más distante del pensar étnico, su explicación la resumen diciendo "lo enviamos a la cárcel para que sienta en carne propia la justicia de los blancos y reconozca como mejor la nuestra". Se trata entonces de un mecanismo que busca reforzar su sentido de pertenencia e identidad, y por efecto de oposición a la justicia blanca, fortalecer la propia 
dinamizan se caracterizan precisamente por provenir de un conocimiento no formal o escolarizado, posibilitando con ello la participación de todos los niveles del saber comunal en la solución del conflicto. Son las prácticas discursivas propias del saber que da la experiencia y no el poder que deviene de la autoridad o cargo los que tenían imponiendo se en el proceso. A ello se debe que casos sencillos de trasgresión de normas culturales resulten involucrando a la comunidad y se resuelvan después de largas deliberaciones en públicas asambleas convocadas por los cabildos o por otro tipo de autoridades étnicas. En este contexto el conflicto se convierte en un espacio privilegiado para socializar el conjunto de la normatividad cultural y para analizar en qué medida el conjunto de los comportamientos sociales están contribuyendo o contraviniendo el orden cultural establecido, y en qué medida ellos están incidiendo en el surgimiento de conductas trasgresoras. Igualmente es una ocasión privilegiada para poner a prueba el saber de los mayores.

Para el derecho moderno en lo atinente a los casos penales, el mecanismo de sanción por excelencia es la prisión. La pretendida validez universal de esta práctica bien vale la pena ser reflexionada.

A mediados de la segunda década del presente siglo un aborigen trobiandés informante del antropólogo Bronislaw Malinosky, encontraba en la sociedad inglesa de la que provenía el investigador, la costumbre más extraña e inexplicable y en su concepción absurda: La practica del encarcelamiento. Su pregunta no se hizo esperar ¿Por qué es necesario encerrar a los hombres?

Medio siglo más tarde el pensador francés Michel Foucault, probablemente desconociendo la existencia de aquel desprevenido aborigen, se hacia la misma interrogación aunque en un sentido más amplio, histórica y socialmente. ¿Por que la práctica del encerramiento en cárceles, manicomios, clínicas, etc? Para abordar la problemática en su sentido arqueológico debió recurrir a la investigación histórica-antropológica, cuyos resultados se encuentran en las obras "El nacimiento de la clínica"”Vigilar y Castigar" y "La verdad y las formas jurídicas".

Pero este interrogante no es exclusivo del ámbito académico, ni de aborígenes de otros continentes, también se da entre grupos étnico $s$ indígenas de Amé- rica Latina, puesto que en ellos tampoco existe intragrupalmente dicha costumbre.

Estos hechos, el de por que algunas sociedades han recurrido al encarcelamiento, en tanto otras no lo han necesitado o siquiera pensado, pone en entre dicho la validez que nuestra sociedad le ha dado a la reclusión como medida universal de seguridad, propia para la rehabilitación o readaptación del infractor. Si como se pretende, la sanción represiva busca la rehabilitación, la inefi- 
cacia del encarcelamiento para el indígena salta a la vista, pues a pesar de ser vivida como un castigo, es una costumbre a la que no le encuentran sentido por no pertenecer al ámbito de las sanciones culturales existentes en su grupo étnico. De aquí que la medida en vez de ser asumida positivamente, se tome totalmente negativa. Es esta la razón para que indígenas de diferentes etnias, reconozcan que ha pesar de haber pagado penas de ocho o diez años de cárcel por el delito de homicidio, aún les queda pendiente la sanción de la étnia a la que pertenecen y se dispongan a asumirla tranquilamente.

En consecuencia, muchos indígenas deben someterse a una doble sanción, la ejercida por la lógica jurídica occidental o positiva, que jamás comprende, pero que acepta como la expresión del poder real dominante, y la practicada por la lógica jurídica propia en la que halla una razón de ser, por haber sido socializado en ella. Pero la sanción en reiteradas ocasiones se toma en ofensa y humillación, como lo revela el caso de un paez que habiendo sido juzgado por intento de homicidio a otro indígena, fue premiado por su buena conducta por el director de la cárcel, sacándolo de la celda para que realizara el oficio de aseador y mesero de sus oficinas y las de sus secretarias, "oficios femeninos" que el indígena interpretaba como "una humillación del blanco" (sic), por haber agredido a su congénere que le ofendió al endilgarle en su comportamiento una actitud femenina.

Los grupos étnicos además de no comprender el por qué del encarcelamiento, tampoco entienden las razones por las cuales el derecho penal colombiano tenga como única sanción a todos los delitos, el encarcelamiento. El robo se paga con cárcel, el homicidio también, las recuperaciones de tierra igualmente y así sucesivamente; lo único que varía, dicen, es el tiempo de la pena.

La pertinencia de la incomprensión deviene del hecho de que entre las etnias, las sanciones son diferenciadas y en ocasiones dependen del tipo de conducta asumida. $\mathrm{O}$ sea que como las conductas consideradas trasgresoras del orden social son producto de causas o motivaciones diferentes, su sanción no puede ser siempre la misma. La sanción para que sea realmente un correctivo, no debe distanciarse tan abstractamente de las causas que trastorna la conducta, porque entre los páez, el hurto (conducta rara), se resarce devolviendo lo robado o su equivalente; si se mata, dependiendo de las circunstancias y modo, con la propia muerte, trabajando para la familia del afectado o con el destierro; si se es pleitero, con una metida al cero; si se es víctima de brujería o maleficio, recurriendo al The'wala (medico páez), y si el maleficio persiste, atacando su causa (la brujería), y llegado el caso, matando su víctima, el brujo.

Pero en la sanción de estas conductas trasgresoras entre las etnias andinas, interviene frecuentemente el cabildo indígena, con procedimientos muy 
particulares; aconsejando en privado a su ejecutor, si reincide en su conducta, amonestándolo públicamente, si esto no es suficiente, algunas etnias, entre ellas los paeces, tienen por costumbre colgar al infractor y azotarlo con ortiga, o metiéndolo en le cepo. Si con estos procedimientos no se logra la restitución del individuo al orden cultural, hecho por demás poco frecuente, no queda más remedio que privarlo de su derecho a la posesión de tierras dentro del resguardo, o condenarlo al ostracismo, o expulsarlo del territorio étnico. Y digo, no queda más remedio, para resaltar que no obstante la drasticidad de algunas sanciones, ellas no pretenden como fin primero el castigo, es más un medio para desarrollar formas de integración y solidaridad social para enfrentar el malo lo considerado como no bueno para la convivencia social. Lo es así porque en estas etnias la trasgresión no es considerada como una pro- piedad inherente del sujeto, ni consecuencia de una voluntad expresa, sino un cuerpo extraño, producto del azar o de las circunstancias a las que están expuestos permanentemente la colectividad y el individuo. El trasgresor es a la vez víctima y victimario.

La persistencia de estas formas de derecho étnico cuya producción y ejercicio cotidiano "pone en cuestión", por lo menos en el orden práctico, los componentes básicos del modelo paradigmático del derecho moderno, o en términos más débiles, lo contrasta, "no se debe a que en la actualidad el derecho estatal se esté rompiendo o tenga fisuras, sino a que el monopolio del derecho entre las etnias por parte del Estado, históricamente ha sido inexistente. En la practica y desde los tiempos de la conquista las etnias indígenas, aplican formas de derecho propias, de aceptación tácita intracomunitaria y al margen o desarticuladamente del Estado.” (Gómez, 1994: 47).

Esta realidad a pesar de su constante práctica cotidiana, desafortunadamente no ha sido aún investigada. Lo que existe en su defecto es multiplicidad de discursos, algunos de ellos disciplinarios, que aislada y/o desarticuladamente intentan explicar algunas de las prácticas que por diversas razones aparecen como de conocimiento público.

Para las ciencias sociales y para el desarrollo de la democracia, la existencia de estos derechos no estatales plantea múltiples problemas a investigar, entre los cuales pueden destacarse: Política e ideológicamente interroga sobre la dinámica de las relaciones de poder entre el derecho estatal y los no estatales, y las implicaciones que tienen la existencia de estos para la aplicación del derecho moderno en el contexto de estados multiétnicos y pluriculturales. Históricamente, pasa por el análisis de las formas de resistencia étnica frente a las prácticas de dominación y sujeción y regulación estatal. Jurídicamente, demanda la investigación de los sistemas de producción y 
reproducción de concepciones culturales singulares para la resolución de conflictos intraetnicos, interétnicos e interculturales y las implicaciones de intervención o no del derecho estatal en ellos y de su regulación mediante la norma escrita. Etnológicamente, se pregunta sobre el proceso de persistencia de estas formas de producción y ejercicio del derecho en la construcción de la etnicidad, en el contexto de un Estado pluricultural y en sus relaciones con los derechos humanos.

Estos interrogantes o problemas distribuidos disciplinariamente, si bien delimitan espacios de observación específicos, se convierten teóricamente en una unidad de análisis, donde sus imbricaciones hacen parte de la problemática, y cuya complejidad obliga a un procesamiento y producción de nuevos discursos antropológicos, jurídicos, filosóficos, al menos así parece requerirlo el acontecer histórico presente. En efecto los nuevos procesos sociales evidencian la intensificación legitimada de movimientos étnicos a nivel mundial, hasta el punto que ha sido necesario la construcción de una legislación supraestatal, que de paso derrumba los discursos precedentes, sobre todo aquellos de las ciencias sociales que vaticinaban la desaparición de las diferencias culturales y étnicas como consecuencia del desarrollo del sistema capitalista.

La dinámica de esta vigorización de lo étnico es un proceso que ha agotado velozmente la eficacia social y política de la normatividad jurídica, cuya respuesta mecanicista lo único que ha producido es una nueva y mayor normatividad sin permitir la consolidación de una nueva configuración cultural donde lo diverso pueda ser potenciado o plenamente desarrollado. El Estado como nación plural tantas veces negado por el mito homogenizador de occidente aparece hoy como proyecto a ser reconstituido.

En la práctica lo que ha generado este reduccionismo jurídico, no obstante la ploriferación y ampliación de normas, es que los individuos, grupos sociales, etnias, desarrollen un conjunto de acciones y actitudes frente a las normas jurídicas que los lleva a las "trasgresiones practicas" y a las "practicas de la trasgresión”. (Lartique e Iturralde, 1993:6). Estos mecanismos de reacción 10 que generalmente hacen es desvirtuar la norma y socializar en cambio las formas de representación cultural de sus prácticas "trasgresoras".

Si bien el peso de estas formas de resolución de conflictos entre las etnias es menor frente a las dominantes u oficiales, no por ello la dinámica sociocultural de lo construido como diverso carece de valor por lo contrario demanda igualmente investigación, máxime si ellas se inscriben en el marco de la problemática del entendimiento intercultural reivindicado en el presente, por los Estados democráticos. "La ineludible pluralidad en materia de prácticas, culturales: lingüísticas, religiosas, medicas, ambientales; plantea la 
necesidad de ir más allá de los postulados republicanos de homogeneidad e igualdad ante la ley. Este problema no se resuelve únicamente en las garantías que la tradición democrática ofrece por la vía de la pluralidad política y de la libertad ciudadana; parecería que siempre hizo falta desarrollar una normatividad funcional que los reconozca y proteja" (Ídem: 6). Más aun cuan- do se conoce que la producción y reproducción de sistemas de gobierno étnico se desarrollan sobre principios distintos a los sistemas democráticos, al igual que sus conflictos se resuelven por la vía de transacciones, mediaciones, conciliaciones, consejos, inscritos en una cosmovisión construida sobre la base de sus propias condiciones culturales de existencia, que norman sus usos y costumbres e incluso las trasgresiones, al mismo tiempo que las reciclan mediante dispositivos culturales siempre en función de restituir el orden social étnico. De no ser así su carácter societal no tendría la denominación de grupo étnico con que actualmente se les reconocen sus especificidades socioculturales y formas de organización social no pro- piamente occidentales.

Estos sistemas de derecho, sus formas de producción y reproducción, las prácticas culturales para su ejercicio, así como usos y costumbres, mecanismos de solución de conflictos (intraétnicos, interétnicos, interculturales o intersocietales), concepción y representación de la justicia y mecanismos de socialización, constituyen objetos de conocimiento para la antropología jurídica que demanda investigaciones al respecto, máxime cuando en Colombia existen (además de las etnias negras ${ }^{3}$ ) cerca de un centenar de etnias indígenas asentadas a lo largo y ancho de su geografía, habitando en todos sus ecosistemas, que poseen sistemas de derecho propios y disímiles.

Solo una investigación a este nivel podrá dar respuesta a los requerimientos perentorios hechos desde la Constitución Nacional y el derecho dominante, a cerca de la conveniencia de regular o no las formas de derecho étnico indígena, de la pertinencia de que dicha regulación se haga mediante la adopción de normas jurídicas escritas, de los efectos que estas tendrían sobre las etnias y el desarrollo de su etnicidad, de la validez e implicaciones de instaurar entre los grupos étnicos los componentes del modelo paradigmático del derecho moderno. Igualmente es necesario redefinir la persistencia del derecho étnico en

3 Si la escasa investigación sobre comunidades negras permitió acuñar en Colombia la frase de "invisibilidad académica" más aún lo esta el conocimiento sobre la existencia o no de formas propias de derecho o de justicia A pesar de esta ausencia no quisiera pasar por alto un hecho sociológico: mientras las estadísticas revelen que un alto porcentaje de homicidios y lesiones personales entre indígenas, blancos, mestizos se realizan después de ingerir alcohol $y / o$ de celebraciones especiales, las fiestas entre grupos negros pareciera no ser un espacio para estos hechos. La fiesta entre estos grupos es un espacio de socialización para la integración y convivencia pacífica. En vez de generar conflictos es un mecanismo para solucionarlos. 
sus intersecciones con los procesos globales y/o estatales. Intersección o espacio donde efectivamente y en la práctica sus sentidos están siendo discutidos, puestos en cuestión, en integración, en articulación, en reconocimiento o exclusión.

Se hace referencia aquí al espacio de intersección en donde se pasa del plano formal del pluralismo jurídico al de la contradicción de sus prácticas cuando el derecho estatal juzga a sujetos étnicos socializados en otras formas culturales de derecho. Es precisamente en estos espacios de juzgamiento construidos por el modelo dominante, donde los ejes problemáticos objetos de investigación se manifiestan con todo su vigor, y se desnuda la naturaleza de las relaciones de sujeción y dominación, que las define. Espacios donde muchas veces en vez de solucionarse el conflicto, lo que se da es un proceder proclive a su acrecentamiento. Un caso reciente -aún en proceso jurídicosirve para funda- mentar esta afirmación. Se omiten los nombres reales y lugar de los hechos por ser todavía un caso no precluido.

Juan Chocué, esposo de Mariana Iscué, comienza a convivir paralelamente con Inés Taquinás. Mariana al darse cuenta recurre al Cabildo, éste recrimina a Juan por su conducta, quien se compromete a cambiar de comportamiento, pero días después se olvida de su promesa. Mariana vuelve al Cabildo que de nuevo recrimina verbal y públicamente a Juan e Inés; sin embargo la relación persiste. El Cabildo estudia la situación y se da cuenta que Inés no tiene esposo y es madre de tres hijos y decide buscarle compañero en la parcialidad, logrando que Roberto se haga cargo de Inés y que ella lo acepte. Sin embargo la solución no satisface a Mariana, quien continúa acudiendo al Cabildo. Este decide finalmente meter a Juan al cepo y advierte a Mariana que no puede hacer nada más. Al resultar inoficiosa la medida, un colono comprendiendo el sufrimiento de Mariana, le recomienda que recurra a la justicia ordinaria. Mariana atendiendo su consejo, procedió inmediatamente al denuncio correspondiente. Actualmente se juzga a Juan por el delito de inasistencia de alimentos, al Cabildo por: violación de los derechos humanos, tortura física (metida en el cepo), íntima coerción personal (obligar a Inés a vivir con Roberto), suplantación de la justicia ordinaria; delitos no existentes en el sistema de derecho páez, exceptuando el de la infidelidad posmarital, que si bien es considerada corno una conducta trasgresora del orden cultural, no se considera corno un acto de oposición social. Al preguntarle a Mariana qué pretendía lograr con el denuncio, respondió mediante una lógica simple pero contundente: "que Juan siga viviendo solo conmigo y sin caer en la cárcel" (sic).

Estos hechos demuestran como en el procesamiento al indígena, la normatividad jurídica, no hace más que continuar su monólogo recivilizatorio iniciado desde la conquista, cuyo fin es homogenizar para dominar, para sojuzgar. 
Con esta forma de proceder la práctica jurídica, y la ley, siguen negando de hecho al sujeto étnico, dando continuidad a un tipo de pensamiento social dominante en nuestra sociedad que sostiene la superioridad del derecho estatal frente a los no estatales o desarrollados bajo su sombra. De aquí que cuando se juzga a un indígena, lo que en la practica jurídica se hace, no es juzgar a una persona, ni sancionar un delito, sino juzgar una cultura, unas formas de actuar y de pensar, mediante una normatividad y un lenguaje tan técnico como oscuro que invalidan la existencia de otros derechos y sentidos culturales.

La exegética jurídica presenta como obstáculo su incapacidad para aceptar el problema como propio de un ámbito que la trasciende, el orden cultural y de las relaciones interculturales, prefiere en cambio unilateralmente hacerlo suyo mediante el reduccionismo de la ley y la norma. El orden de la cultura reducido al orden de lo jurídico amparado en el poder dominante de la administración de la justicia nacional.

Reduccionismo jurídico cuyo poder ha conducido a! reduccionismo antropológico a través de la figura del dictamen pericia! antropológico, baste un ejemplo: Un destacado jurista colombiano en asocio con un antropólogo defensores de los derechos humanos y de las reivindicaciones étnicas, lograron el "milagro" de la absolución en 1979, de dirigentes indígenas del Consejo Regional Indígena del Cauca (CRIC), demostrando su calidad de semisalvajes, al tenor de lo establecido en la Ley 89 de $1890 .{ }^{4}$

Logros similares se han obtenido declarándolos inimputables jurídicamente por ser indígenas o por inmadurez psicológica. Se les ha salvado de su conde- na jurídica a cambio de continuar condenándolos culturalmente a través de una absurda homología que confunde diversidad cultural o formas de concebir el mundo y comportarse de acuerdo a él, con "incapacidad para comprender la ilicitud de su conducta”, debido a su carácter de indígena o a su alteración mental etc.

"Justicia maltrecha y recortada, lamentable para el devenir histórico de la diversidad y la plurietnicidad que caracteriza nuestro pais, aunque "exitosa" para los sujetos inculpados. Proceso jurídico del dictamen antropológico que lleva a pensar más en los fines que en los medios, puesto que generalmente lo que interesa es lograr a toda costa la libertad de los procesados, sin pensar que las argumentaciones, antes que posibilitar avanzar en el conocimiento del problema, lo que hace es tenderle trampas y acentuar los obstáculos que le subyacen. De abi que la teoría existente en Colombia, incline la balanza del debate hacia

4 Esta ley, de la que tuvieron que valerse algunos abogados para defender a indígenas apresados en las generalizadas recuperaciones (invasiones para el derecho agrario) de tierras de terratenientes, dió origen en Colombia al dictámen pericial antropológico. Este hecho ha dado lugar a pensar que el prOblema se resuelve a través de este instrumento coyuntural, olvidándose que el mismo es de orden estructural. 
el derecho, al perfeccionamiento del proceso, al tecnicismo o reduccionismo jurídico, que de igual manera no permite que aflore el asunto en cuestión, porque lo que se puede observar es que el problema es fundamentalmente ideológico y politico." (Gómez, 1992:39).

La imposibilidad de ver al sujeto étnico en su diferencia, en su concreción, asumiéndolo como lo exótico, o sea desvalorándolo para poder negarlo y proceder a recivilizarlo, modelarlo a nuestra imagen y semejanza, colonizarlo. El ritual jurídico de administrarles justicia tal vez no hace otra cosa que juzgar a quienes han sido previamente sojuzgados, procesar a quienes "nacieron procesados", ratificando en el ámbito del sistema judicial nacional lo que también existe en el campo de las demás relaciones sociales signadas por las configuraciones ideológicas de dominación.

En consecuencia se tiene que el problema no se haya en el campo de lo jurídico, existe en algo mas allá del derecho, se instaura en lo ideológico, en lo dominante de las practicas discursivas y sistema de clasificación "jurídica" que de las etnias hacen el Estado y sociedad nacionales.

Es en este orden de ideas que las prácticas jurídicas a través de las cuales se procesan conflictos culturales o regulan relaciones interculturales se convierten también en un cuerpo de observaciones y reflexión antropológico-jurídico.

El conjunto de estos ámbitos de observación, interrogantes y ejes problemáticos deben ser analizados en relación con la normatividad jurídica supraestatal como la atinente a los derechos humanos, y con el derecho estatal, cuya hermenéutica pasa por el prisma de la dinámica social y política entre homogeneidad y diversidad cultural, entre procesos hegemónicos y practicas sociales discursivas alternativas, entre los límites (resistencias?) interpuestos a lo hegemónico por los múltiples sentidos de identidad cultural, presentes en los sistemas de derecho de las diferentes etnias.

Independientemente de los caminos o los atajos utilizados para abordar esta problemática, ninguno de ellos debe soslayar los problemas jurídicoantropológicos que se presentan cuando se procede a juzgar un sujeto a través de un sistema de derecho que le es ajeno, extraño, o impuesto, y que no comprende, por haber sido socializado en otro de "naturaleza" distinta, o en términos menos fuertes, de contenidos o concepciones opuestas.

\section{BIBLIOGRAFIA}

Barona, Guido. Sujeción y legitimidad. Los paradigmas de la invención de América. Bogotá, Colcultura, 1994.

Constitución Nacional de Colombia.. Bogotá, 1991. 
Clastres, Pierre. La societé contre IEtat. Paris. ED. Minuit, 1974. Clastres, Pierre. Investigaciones de Antropología Política. Barcelona. Ed. Gedisa, 1980.

Chenaut, Victoria y Sierra, María Teresa. El campo de investigación de la antropología jurídica. En: Nueva antropología. Revista. Volumen XIII, No 43. México, 1992.

Dalh, Robert. Dilemas de la democracia pluralista. New Haven, 1982. .

Foucault, Michael. La verdad y las formas jurídicas. Editorial Gedisa. Barcelona, 1980

Foucault, Michel. Vigilar y Castigar. México. Siglo XXI Editores, 1978.

Gómez, Herinaldy. Derecho y Cultura en el Juzgamiento de los indígenas. En: Identidad. Instituto Colombiano de Antropología. Bogotá, 1989.

Gómez, Herinaldy. Aportes Antropológicos a la teoría y la práctica de la Antropología Juridica en Colombia. En: Normas Formales: Costumbres

Gómez, Herinaldy. El Derecho Indígena: Una relación de poder. En: Problemas políticos latinoamericanos. Revista No.l. Facultad de Humanidades. Universidad del Cauca, 1993.

Lartique, François e Iturralde, Diego. Antropologia jurídica: perspectivas de investigación. Ponencia presentada en el XIII Congreso Internacional de Ciencias Antropológicas y Etnológicas (CICAE). México, 1993.

Organización internacional del Trabajo. Convenio sobre Pueblos Indígenas y tribales en países independientes. Ginebra, 1989.

Reyes Echandia, Alfonso. Derecho Penal y Cultura. En: Grupos Étnicos, Derecho y Cultura. Cuadernos del Jaguar. Funcol. Bogotá, 1987

Sánchez Parga, José. La trama del poder en la comunidad andina. Ed. Centro Andino de Educación Popular. Quito, 1986.

Sánchez Parga, José. Etnia Poder y Diferencia. Ediciones ABYA YALA. Quito, 1980.

Stavenhagen, Rodolfo. Los derechos de los indigenas: algunos problemas conceptuales. En: Nueva antropología. Revista. Volumen XIII, No 43. México, 1992. 